\title{
Structural Characterization of Borate Glasses Containing Zinc and Manganese Oxides
}

\author{
Manisha Pal ${ }^{1}$, Baishakhi Roy ${ }^{2}$, Mrinal Pal ${ }^{3,4}$ \\ ${ }^{1}$ Department of Physics, Sarojini Naidu College for Women, Kolkata, India \\ ${ }^{2}$ Department of Physics, The University of Burdwan, West-Bengal, India \\ ${ }^{3}$ CSIR-Central Mechanical Engineering Research Institute, Durgapur, India \\ ${ }^{4}$ The University of Burdwan, Bardhaman, India \\ E-mail:m_pal@cmeri.res.in \\ Received January 31, 2011; revised April 22, 2011; accepted May 6, 2011
}

\begin{abstract}
We have investigated the effect of inclusion of two transition metal ions (TMI) on structure and optical properties of borate glass system having composition $x \mathrm{MnO}_{2}-y \mathrm{ZnO}-(100-x-y) \mathrm{B}_{2} \mathrm{O}_{3}(9 \leq x \leq 12,36 \leq y$ $\leq 48$ ) prepared by melt quenched route. Thermal study by using a differential scanning calorimeter (DSC) reveals that the glass transition temperature $(\mathrm{Tg})$ and crystallization temperature $(\mathrm{Tc})$ of the glasses increases with the increase of borate content in the system. Fourier transform infrared (FTIR) spectra indicate that inclusion of TMI produces $\mathrm{BO}_{3}$ and $\mathrm{BO}_{4}$ structural units by breaking the boroxol $\left(\mathrm{B}_{3} \mathrm{O}_{6}\right)$ ring. The optical band gap energy estimated from ultraviolet-visible spectra shows a decreasing tendency when TMI are incorporated in the borate structure.
\end{abstract}

Keywords: Borate Glass, Differential Thermal Analysis (DTA), Infrared (IR) Spectroscopy, Optical Band Gap

\section{Introduction}

Glasses are receiving considerable attention due to their unique properties like hardness, good strength, transparency and excellent corrosion resistance. X-ray diffraction (XRD), infra-red spectroscopy (IR), differential scanning calorimetry (DSC) studies has been extensively employed over the years to investigate the structure of glasses [1-4]. Borate glasses, in particular, have been the subject of numerous infra-red studies due to their structural peculiarities [5-8]. In pure $\mathrm{B}_{2} \mathrm{O}_{3}$ glass structure most of the boron is involved in $\mathrm{B}_{3} \mathrm{O}_{6}$ (boroxol) ring. Addition of modifier breaks boroxol ring and thereby produced $\mathrm{BO}_{3}$ and $\mathrm{BO}_{4}$ units $[6,8]$. In addition, modifier also changes the physical properties along with structural modifications.

Recently, the study of oxide glasses doped with transition metal ions (TMI) has received considerable attention due to their attractive combination of physical and chemical properties. TMI doped borate glasses have application in microelectronics, optical glasses and solid state laser [9-11]. Continued effort for the development of new glassy materials either by doping or by adding TMI, and the study of their novel properties is highly relevant due to their potential applications in various technological fields $[12,13]$. Keeping in mind the very fact of creating novel functionalities we have chosen an uncommon glass system. We report here the preparation, structural characterization and optical properties of manganese and zinc oxide containing $\mathrm{B}_{2} \mathrm{O}_{3}$ glass with an intention to precipitate $\mathrm{Mn}$-doped $\mathrm{ZnO}$ crystal in the borate glass matrix, which may lead to a new composite spintronics material.

\section{Experimental Procedure}

\subsection{Preparation}

Multicomponent transition metal oxide glasses containing $\mathrm{MnO}_{2}-\mathrm{ZnO}-\mathrm{B}_{2} \mathrm{O}_{3}$ having different compositions, presented in Table 1, have been prepared from analytical grade precursors $\mathrm{MnO}_{2}, \mathrm{ZnO}$ and $\mathrm{B}_{2} \mathrm{O}_{3}$. Batches of $5 \mathrm{gm}$ sample were prepared by taking weighted amounts of three oxides in an alumina crucible and melting mixture in a precisely controlled high temperature furnace (Thermolyne type 46100 ) at a temperature $1200^{\circ} \mathrm{C}$ in ordinary air atmosphere. Melted mixtures were repeatedly swirled to ensure complete homogenization. The 
Table 1. Nominal chemical composition of the glasses (mol\%).

\begin{tabular}{ccc}
\hline $\mathbf{M n O}_{2}$ & $\mathbf{Z n O}$ & $\mathbf{B}_{2} \mathbf{O}_{\mathbf{3}}$ \\
\hline 9 & 36 & 55 \\
10 & 40 & 50 \\
11 & 44 & 45 \\
12 & 48 & 40 \\
\hline
\end{tabular}

glasses were prepared by quenching the melted materials between two brass plates.

\subsection{Characterization}

X-ray diffraction technique was used to check for possible crystallinity of the samples after quenching and annealing. We have utilized Philips (Philips PW 1050/51) $\mathrm{X}$-ray powder diffractometer with $\mathrm{CuK} \alpha$ radiation. Differential scanning calorimetry study was carried out on a Schimazdu DSC-60 in the temperature range $30^{\circ} \mathrm{C}-600^{\circ} \mathrm{C}$ at a constant rate $10^{\circ} \mathrm{C} / \mathrm{min}$. under ordinary air atmosphere using aluminum pan. The accuracy in determining the Tg and Tc were $\pm 3^{\circ} \mathrm{C}$. Scanning electron microscopy (SEM) study was performed in a Hitachi made instrument (S-3000N). Vibrational spectra of various asprepared glasses were obtained by $\mathrm{KBr}$ pellet technique in the range $400-4000 \mathrm{~cm}^{-1}$ using a Nicolet Magma-IR (750, Series II) spectrophotometer. The optical absorption spectra of as-prepared glass samples were recorded at room temperature in the range $200-800 \mathrm{~nm}$ using a double beam Hitachi spectrophotometer (model U3410).

\section{Result and Discussions}

\subsection{XRD and SEM Study}

Figure 1 presents the XRD pattern of the sample containing $45 \% \mathrm{~B}_{2} \mathrm{O}_{3}$ which is typical for other samples. XRD patterns of all the as-prepared samples show no sharp Bragg's peak, but only a broad diffuse hump around low angle region. This is the clear indication of amorphous nature within the resolution limit of XRD instrument. Scanning electron microscopy studies of these as-prepared samples also exhibit a clear surface without the presence of any microstructure. Figure 2 shows a typical SEM micrograph of as-prepared sample having $55 \% \quad \mathrm{~B}_{2} \mathrm{O}_{3}$. Absence of microstructure in SEM picture also indicates the amorphous as well as homogeneous nature of the samples.

\subsection{DSC Analysis}

Figure 3 shows the DSC curve of as-prepared sample

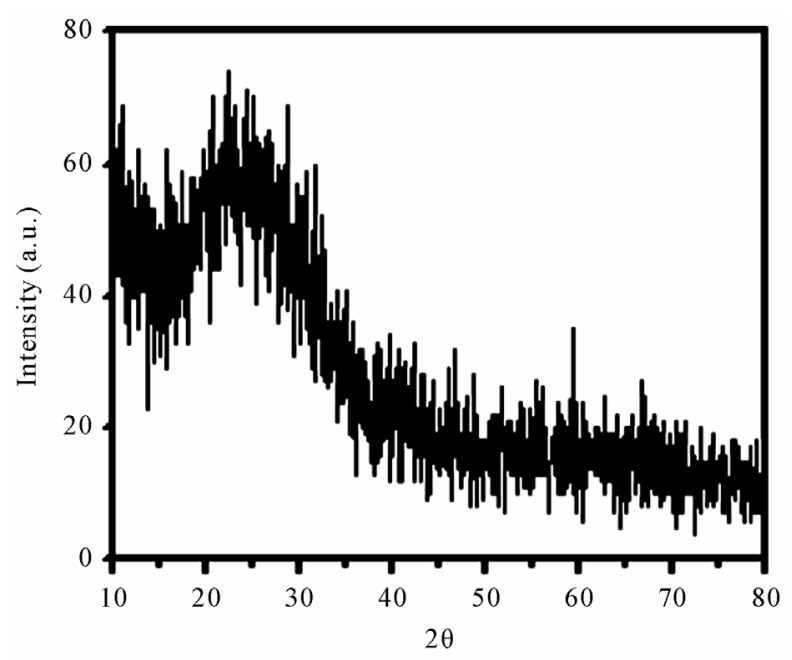

Figure 1. XRD patterns of the sample containing $45 \mathrm{~mole} \%$ $\mathbf{B}_{2} \mathbf{O}_{3}$.

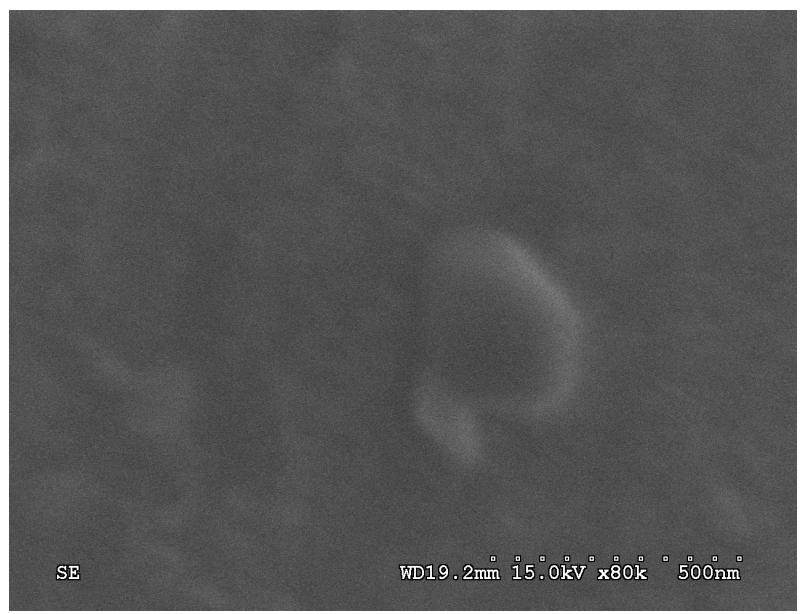

Figure 2. SEM micrograph of as-prepared sample having 55 mole $\% \mathrm{~B}_{2} \mathrm{O}_{3}$.

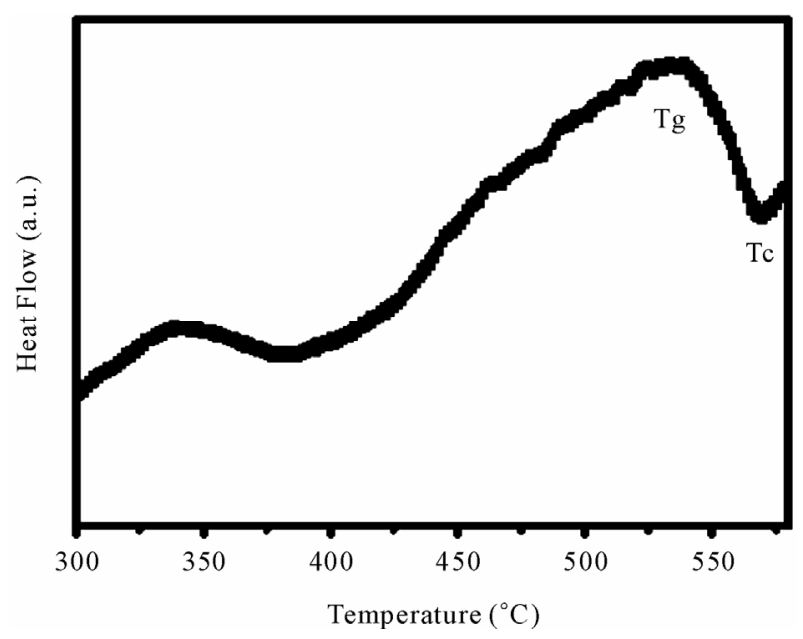

Figure 3. Differential scanning calorimetric curve of 40 mol\% $\mathrm{B}_{2} \mathrm{O}_{3}$ glass. 
having $40 \mathrm{~mol} \% \mathrm{~B}_{2} \mathrm{O}_{3}$. This curve clearly shows one endothermic peak and one exothermic peak.

The endothermic peak corresponds to the glass transition while the exothermic peak indicates the crystallization point of the glass. The glass transition ( $\mathrm{Tg}$ ) as well as crystallization temperatures (Tc) are estimated by the slope intercept method. The nature of the DSC curves is typical for other glass compositions.

Thermal study of the glasses were performed because any change in the coordination number of network forming atoms, or the formation of nonbridging oxygen, is known to be reflected in the Tg. Figure 4 illustrates the variation of $\mathrm{Tg}$ and Tc with compositions. DSC study reveals that both $\mathrm{Tg}$ and $\mathrm{Tc}$ increase monotonically with the increase of $\mathrm{B}_{2} \mathrm{O}_{3}$ content, which is the network former here. It is reported that generally $\mathrm{Tg}$ and $\mathrm{Tc}$ increases with the increase of network former/glass former [14] which is observed in this present study also. However several reports of germanate anomaly are there which shows a decrease in $\mathrm{Tg}$ with the increase of $\mathrm{GeO}_{2}$ content in the glass system [15]. A maximum in the Tg vs. $\mathrm{B}_{2} \mathrm{O}_{3}$ content curve is also reported [16]. It is believed that $\mathrm{Tg}$ is depend on the strength of chemical bonds in the structure. TMI in general, plays the role of a network modifier and non-bridging oxygen increases with the increase of TMI content in the glass system. Increase of non-bridging oxygen indicates the breaking of chemical bonds, which in turn decrease the $\mathrm{Tg}$. Increase of $\mathrm{Tg}$ with the increase of network former, in other words, decrease of TMI, indicates the increase of strength and connectivity of the glass structure in this case.

\subsection{FTIR Study}

Infrared spectroscopy has proved to be an important tool for the investigation of structure and dynamics of disorder materials. IR spectra of materials may help to get the idea of the nature of vibration in a disorder system [16]. The room temperature vibration spectra of the glasses were obtained using $\mathrm{KBr}$ pellet technique in the range 400 - $4000 \mathrm{~cm}^{-1}$. A typical FTIR spectrum of the as-prepared glass containing $50 \% \mathrm{~B}_{2} \mathrm{O}_{3}$ is shown in Figure 5. As expected, these spectra exhibit broad absorption bands as a consequence of the general disorder in the network, mainly due to a wide distribution of structural units occurring in these glasses.

The band marked as A attributed to the presence of transition metal ions in bi-valent state $\left(\mathrm{Zn}^{2+}, \mathrm{Mn}^{2+}\right)$. The absorption bands marked as B, C and D are due to borate matrix. Details of the appeared peaks are presented in Table 2. The peak assignment is consistent with other published work [17-19]. Absence of peak around 806 $\mathrm{cm}^{-1}$, which is clear from the inset of Figure 5, indicates

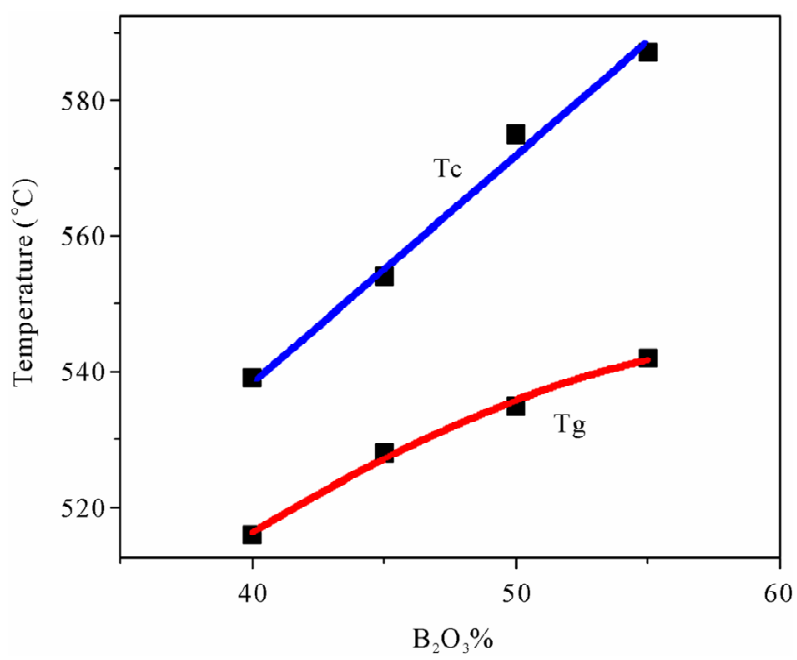

Figure 4. Compositional dependency of glass transition and crystallization temperature (Line connecting the data points is a guide for the eye).

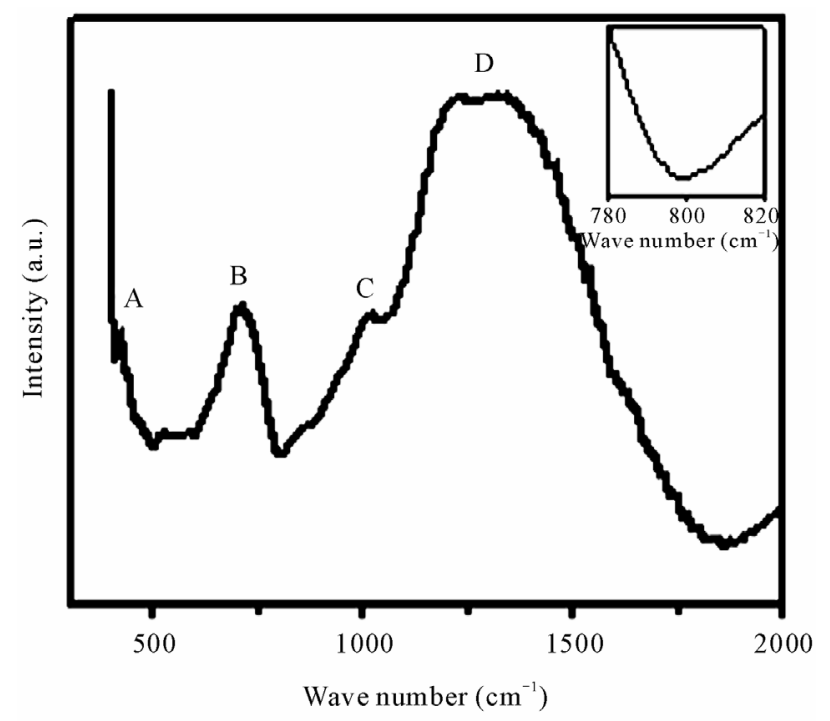

Figure 5. Room temperature FTIR spectra of zinc manganese borate glasses for $50 \mathrm{~mol} \% \mathrm{~B}_{2} \mathrm{O}_{3}$. Inset: Magnified version of FTIR curves to prove the absence of boroxol rings.

Table 2. Various absorption peak positions obtained from FTIR spectra.

\begin{tabular}{ccl}
\hline Band & $\begin{array}{r}\text { Position of Band } \\
\left(\mathrm{cm}^{-1}\right)\end{array}$ & \multicolumn{1}{c}{ Assignment } \\
\hline A & $\sim 425$ & $\begin{array}{l}\text { Vibration of metal cations such as } \\
\mathrm{Zn}^{2+} / \mathrm{Mn}^{2+}\end{array}$ \\
B & $\sim 700$ & Bending of B-O-B linkage \\
C & $\sim 1020$ & B-O stretching of BO $\mathrm{B}_{4}$ tetrahedra \\
D & $\sim 1280$ & $\begin{array}{l}\text { Asymmetric stretching of B-O of } \\
\text { trigonal BO }\end{array}$ \\
\hline
\end{tabular}


that borate network does not contain any boroxol ring [17]. The broadness of D band is due to the presence of $\mathrm{Zn}^{2+}$ in the system. Generally, in pure $\mathrm{B}_{2} \mathrm{O}_{3}$ glass most of the boron is involved in $\mathrm{B}_{3} \mathrm{O}_{6}$ boroxol rings [18]. The addition of TMI breaks these rings and increasingly $\mathrm{BO}_{3}$ and $\mathrm{BO}_{4}$ units are formed which is, reflected in our samples also [20]. No detectable variation in peak positions and band shape are observed with the change of composition.

\subsection{Optical Absorption Study}

The fundamental optical band gap of the glasses has been computed based on their UV-Vis absorption spectra, for understanding their optically induced transitions. There are two types of optical transition, which can occur at the fundamental absorption edge of crystalline and noncrystalline materials. They are direct and indirect transitions. In both the cases, electromagnetic waves interact with the electrons in the valence band, which are raised across the fundamental band gap to the conduction band. For photon energies hv just above the fundamental edge, the absorption $\alpha$ follows the standard relation,

$$
\alpha=A\left(h v-E_{g}\right)^{1 / 2} / h v
$$

where $A$ is a constant and $E_{g}$ is defined as the energy band gap. A typical plot of $(\alpha h v)^{2}$ versus hv for the glass having $55 \% \mathrm{~B}_{2} \mathrm{O}_{3}$ is presented in Figure 6. Extrapolation of this plot to $\alpha^{2}=0$ gives the optical band gap $E_{g}$ for direct transition. We have estimated the optical band gap for all the glasses, which varies from $3.45-4.05 \mathrm{eV}$ for direct transition while $\mathrm{B}_{2} \mathrm{O}_{3}$ content changes from $40 \%$ $55 \%$. The value of $E_{g}$ for indirect transition is obtained by extrapolation of $(\alpha h v)^{1 / 2}$ versus $h v$ plot to $\alpha^{1 / 2}=0$ [21]. The optical band for indirect transition varies from 3.39 - $3.60 \mathrm{eV}$ while $\mathrm{B}_{2} \mathrm{O}_{3}$ content changes from $40 \%$ $55 \%$. Figure 7 reveals the variation of optical bandgap with the change of composition. It can be observed from Figure 7 that both the direct and indirect band gap increases with the increase of $\mathrm{B}_{2} \mathrm{O}_{3}$. In other words, the optical bandgap decreases with the increase of TMI concentration. This can be attributed to the structural changes that are taking place with the introduction of TMI. Inclusion of TMI in borate structure may create some defect states in the midgap, which is responsible for the decrease of bandgap. The broadness of the absorption edge may be due to the presence of localized state in the band tails.

This paper is a part of more general study concerning the synthesis, structural characterization and optical study of borate glass system. It is noteworthy to mention here that we have annealed one glass sample at $500^{\circ} \mathrm{C}$ for $60 \mathrm{~min}$. XRD pattern of annealed sample confirms the

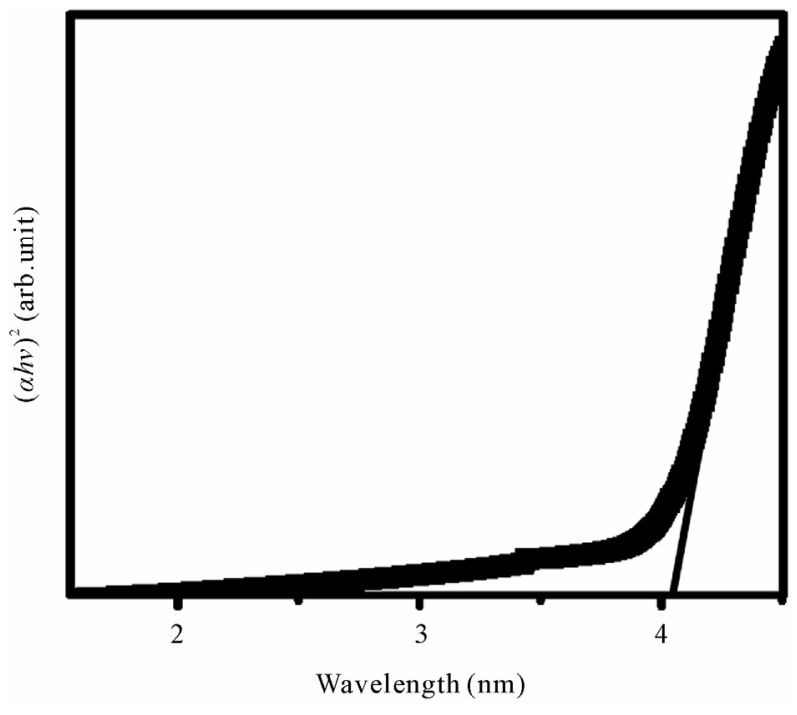

Figure 6. $(\alpha h \gamma)^{2}$ versus $h \gamma$ plot for the glass containing 55 $\mathrm{mol} \% \mathrm{~B}_{2} \mathrm{O}_{3}$.

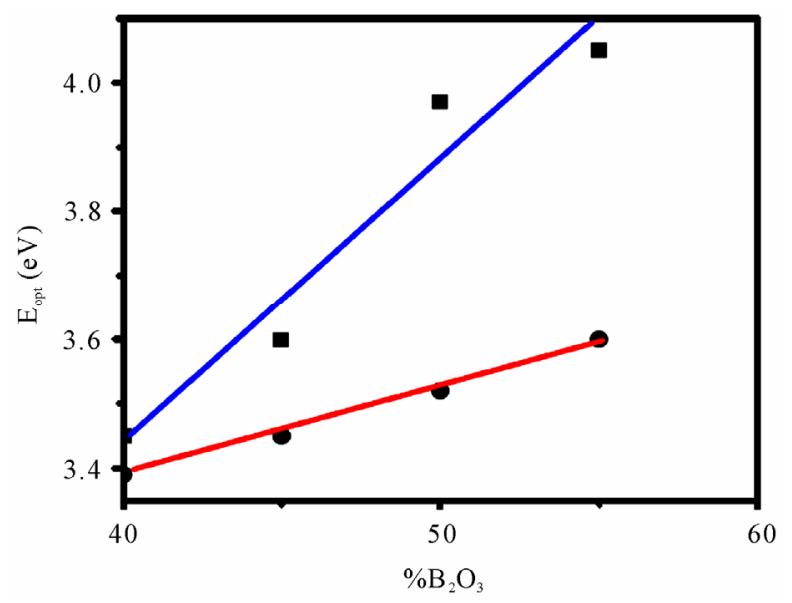

Figure 7. Compositional dependency of optical bandgap Blue line (ø): Direct transition, Red line (•): Indirect transition (Line connecting the data points is a guide for the eye).

precipitation of nanocrystalline $\mathrm{Mn}$-doped $\mathrm{ZnO}$, which also shows magnetization at room temperature. This result indicates the possibility towards the development of borate based spintronic materials. Details of the magnetization are reported elsewhere [22].

\section{Conclusions}

In conclusion, we are able to prepare series of uncommon manganese zinc oxide containing $\mathrm{B}_{2} \mathrm{O}_{3}$ glasses through melt-quenched technique and report the experimental investigation of thermal stability and spectroscopic studies. Both the x-ray diffraction and SEM studies confirm the amorphous nature of the as-prepared 
glasses. The effect of TMI dopping on structure and optical property is discussed. In addition, we have demonstrate that magnetic $\mathrm{Mn}$-doped $\mathrm{ZnO}$ nanoparticles can be precipitated in the borate matrix if the glasses annealed at particular temperature.

\section{Acknowledgements}

Financial support from the project (No.: CSR/AO/MUM/ CRS-M-144/08/423) of UGC-DAE Consortium for Scientific Research, Govt. of India, is gratefully acknowledged. The authors also thank the DST Unit on Nanoscience of Indian Association for the Cultivation of Science, Kolkata, India for extending their DSC facility.

\section{References}

[1] A. Pan and A. Ghosh, "A New Family of Lead-Bismuthate Glass with a Large Transmitting Window," Journal of Non-Crystalline Solids, Vol. 271, No. 1-2, 2000, pp. 157-161. doi:10.1016/S0022-3093(00)00111-3

[2] Š. Jiri, K. Ladislav, M. Petr, M. Lionel, R. Bertrand and G. Ivan, "Structure and Properties of $\mathrm{MoO}_{3}$-Containing Zinc Borophosphate Glasses," Journal of Non-Crystalline Solids, Vol. 355, No. 16-17, 2009, pp. 970-975. doi:10.1016/j.jnoncrysol.2009.04.017

[3] C. W. Adrian, "Borate Structures: Crystalline and Vitreous," Physics and Chemistry of Glasses-European Journal of Glass Science and Technology Part B, Vol. 51, No. 1, 2010, pp. 1-39.

[4] M. Pal, "Structure and Physical Properties of Sodium Antimony Germinate Glasses," Journal of Materials Research, Vol. 11, No. 7, 1996, pp. 1831-1835. doi:10.1557/JMR.1996.0231

[5] W. L. Konijnendijk and J. M. Stevels, "Structure of Borate and Borosilicate Glasses," In: L. D. Pye, V. D. Fréchette and N. J. Kreidl, Eds., Borate Glasses: Structure, Properties, Applications, Plenum Press, New York, 1978, p. 259.

[6] I. Kashif, H. Farouk, A. S. Aly and A. M. Sanad, "Differential Scanning Calorimetry and Infrared Study of Barium Borate Glass Containing Transition Elements," Physics and Chemistry of Glasses, Vol. 32, No. 2, 1991, pp. 77-78.

[7] A. C. Hannon, D. I. Grimley, R. A. Hulme, A. C. Wright and R. N. Sinclair, "Boroxol Groups in Vitreous Boron Oxide: New Evidence from Neutron Diffraction and Inelastic Neutron Scattering Studies," Journal of Non-Crystalline Solids, Vol. 177, No. 1, 1994, pp. 299-316. doi:10.1016/0022-3093(94)90544-4

[8] D. L. Griscom, "Borate Glass Structrure," In: L. D. Pye, V. D. Fréchette and N. J. Kreidl, Eds., Borate Glasses: Structure, Properties, Applications, Plenum Press, New York, 1978, p. 11.

[9] C. Li and Q. Su, "Action of Co-Dopant in Electron-
Trapping Materials: The Case of $\mathrm{Sm}^{3+}$ in $\mathrm{Mn}^{2+}$ Activated Zinc Borosilicate Glasses,' Applied Physics Letters, Vol. 85, No. 12, 2003, pp. 2190-2192. doi:10.1063/1.1797562

[10] J.-M. Wu and H.-L. Huang, "Microwave Properties of Zinc, Barium, and Lead Borosilicate Glasses," Journal of Non-Crystalline Solids, Vol. 260, No. 1-2, 1999, pp. 116124. doi:10.1016/S0022-3093(99)00513-X

[11] L. D. Bogomolova and M. P. Glassova, "The Impurity Effects in Vanadate Semiconducting Glasses," Journal of Non-Crystalline Solids, Vol. 37, No. 3, 1980, pp. 423-426. doi:10.1016/0022-3093(80)90079-4

[12] M. Pal, D. Chakravorty and A. Bhowmik, "Structural Study of Iron Borate Glasses Containing $\mathrm{NiO}$ and $\mathrm{ZnO}$," Journal of Materials Research, Vol. 13, No. 11, 1998, pp. 3287-3292. doi:10.1557/JMR.1998.0447

[13] L. Aleksandrov, R. Iordanova and Y. Dimitriev, "Glass Formation in the $\mathrm{MoO}_{3}-\mathrm{La}_{2} \mathrm{O}_{3}-\mathrm{B}_{2} \mathrm{O}_{3}$ System," Physics and Chemistry of Glasses, Vol. 48, 2007, p. 242.

[14] R. M. Almedia and J. D. Mackenzie, "Vibrational Spectra and Structure of Fluorozirconate Glasses," Journal of Chemical Physics, Vol. 74, No. 11, 1981, pp. 5954-6537. doi: $10.1063 / 1.441033$

[15] S. Sakka and K. Kamiya, "Structure of Alkali Germanate Glasses Studied by Spectroscopic Techniques," Journal of Non-Crystalline Solids, Vol. 49, 1982, p. 103. doi:10.1016/0022-3093(82)90110-7

[16] P. Becker, "Thermal and Optical Properties of Glasses of the System $\mathrm{Bi}_{2} \mathrm{O}_{3}-\mathrm{B}_{2} \mathrm{O}_{3}$," Crystal Research and Technology, Vol. 38, No. 1, 2003, pp. 74-82. doi:10.1002/crat.200310009

[17] A. H. Verhoef and H. W. den Hartog, "A Molecular Dynamics Study of $\mathrm{B}_{2} \mathrm{O}_{3}$ Glass Using Different Interaction Potentials," Journal of Non-Crystalline Solids, Vol. 146, 1992, pp. 267-278. doi:10.1016/S0022-3093(05)80501-0

[18] S. Ram, "Infrared Study of the Dynamics of Boroxol Rings in the Crystallization of $\mathrm{BaFe}_{12} \mathrm{O}_{19}$ Microcrystal in the Borate Glass," Physical Review B, Vol. 51, No. 10, 1995, pp. 6280-6286. doi:10.1103/PhysRevB.51.6280

[19] N. M. Bobkoval and S. A. Khot'ko1, "Zinc Oxide in Borate Glass-Forming Systems," Glass and Ceramics, Vol. 62, No. 5-6, 2005, pp. 167-170. doi:10.1007/s10717-005-0064-7

[20] W. Soppe, J. Kleerebezem and H. W. den Hartog, "Raman Spectroscopy Study of $\left(\mathrm{B}_{2} \mathrm{O}_{3}\right)_{1-x-y}\left(\mathrm{Li}_{2} \mathrm{O}\right)_{x}\left(\mathrm{Li}_{2} \mathrm{Cl}_{2}\right)_{\mathrm{y}}$ and $\left(\mathrm{B}_{2} \mathrm{O}_{3}\right)_{1}-x-y\left(\mathrm{Li}_{2} \mathrm{O}\right)_{x}\left(\mathrm{Cs}_{2} \mathrm{O}\right)_{y}$, , Journal of Non-Crystalline Solids, Vol. 93, 1987, p. 142. doi:10.1016/S0022-3093(87)80034-0

[21] L. Edwards, M. Gouterman and X. V. Porphyrins, "Vapor Absorption Spectra and Stability: Phthalocyanines," Journal of Molecular Spectroscopy, Vol. 33, No. 2, 1970, pp. 292-310. doi:10.1016/0022-2852(70)90040-8

[22] M. Pal, "Borate Based Spintronic Materials in Bulk Form above Room Temperature," Journal of Surface Science and Technology, Vol. 21, No. 1-2, 2005, pp. 91-96. 